\title{
ANÁLISE ERGONÔMICA APLICADA NAS SALAS DE DESENHO TÉCNICO E PROJETO DO ENSINO SUPERIOR: PROPOSTA SALA MODELO
}

\author{
Karla Laiany de Lima Alves (1); \\ Gustavo Aguillar Teixeira (2); \\ Byanca Souza Rego (3); \\ Beliza Soares Ferraz Brígido (4) \\ (1) ICF - Instituto Camillo Filho, Graduanda em Design de Interiores \\ E-mail: karlalaiany@gmail.com \\ (2) IPOG - Instituto de Pós-Graduação e Graduação, SENAC, Especialista em Iluminação, \\ Design de Interiores e Design de Mobiliário \\ E-mail: gustav.aguillar@gmail.com \\ (3) ICF - Instituto Camillo Filho, Graduanda em Design de Interiores \\ E-mail: byancasouza2111@gmail.com \\ (4) UFPE - Universidade Federal de Pernambuco, Mestre em Ergonomia \\ E-mail: belizaferraz@yahoo.com.br
}

\begin{abstract}
RESUMO
A existência de lacunas nas aplicações e adequações ergonômicas em ambientes de ensino pode dificultar ou inviabilizar o processo de aprendizagem. Deste modo, este trabalho teve por objetivo analisar ergonomicamente uma sala de pranchetas em uma Instituição de Ensino Superior, sob a ótica da Metodologia de Avaliação Ergonômica do Ambiente Construído (MEAC), proposta por Villarouco (2008), juntamente com a aplicação de conhecimentos da antropometria e da biomecânica ocupacional, buscando resultados que possam fornecer indicações e hipóteses satisfatórias para melhoria e adequação dos espaços utilizados no processo de ensino-aprendizagem de desenho técnico.
\end{abstract}

\section{ABSTRACT}

The gaps in ergonomic applications and adaptations, in teaching environments, can hinder or derail the process of learning. In this way, this study aimed to analyze ergonomically a drawing board room in a higher education institution from the perspective of Ergonomic Assessment Methodology of the Built Environment (MEAC) proposed by Villarouco (2008) along with the application of knowledge of anthropometry and Occupational Biomechanics, seeking results that can provide information and assumptions satisfactory for improvement and adaptation of spaces used in the teaching-learning process of technical drawing. 


\section{INTRODUÇÃO}

A Ergonomia é uma disciplina científica que estuda as interações das pessoas com outros elementos do sistema, fazendo aplicações da teoria, princípios e métodos de projeto, com o objetivo de melhorar o bem-estar humano e o desempenho global do sistema (DUL $E$ WEERDMEESTER, 2012). Sabe-se que a falta de efetivação aos preceitos da Ergonomia pode acarretar custos humanos de carga cognitiva, psíquica e física. Em contrapartida, quando aplicados corretamente, possibilitam maximizar o conforto, a segurança e satisfação, minimizando os constrangimentos e potencializando o desempenho da tarefa, do rendimento e da produtividade entre o homem-ambiente-tarefa (PEQUINI, 2007).

$\mathrm{Na}$ avaliação de ambientes construídos, a Ergonomia difere das outras áreas do conhecimento pelo seu caráter interdisciplinar e pela natureza aplicada. $O$ caráter interdisciplinar significa que a Ergonomia se apoia em diversas áreas do conhecimento humano, para compreensão das atividades realizadas, considerando o contexto e as diversidades individuais dos participantes. O caráter aplicado configura-se na adaptação do posto de trabalho e do ambiente às características e necessidades do trabalhador (DUL $E$ WEERDMEESTER, 2012).

Uma completa avaliação ergonômica engloba vários condicionantes fundamentais que se apresentam como embasamento essencial, quando se trata de avaliar o ambiente sob a ótica da Ergonomia. Tais conceitos englobam conforto ambiental, layout, segurança, acessibilidade, posto de trabalho, mobiliário e percepção dos usuários. Sendo assim se faz necessária à aplicação de uma metodologia específica que vislumbre tais necessidades. Partindo desse pressuposto buscou-se por referências na Metodologia Ergonômica do Ambiente Construído (MEAC), proposta por Villarouco (2008), juntamente com aplicação de conhecimentos da Antropometria e da Biomecânica Ocupacional. Referências essas necessárias para identificação das variáveis do ambiente e do posto de trabalho, assim como os pontos de desconforto provindo das posturas inadequadas, permitindo proposições e recomendações satisfatórias para melhoria e adequação do ambiente, que contemplem as exigências das atividades, considerando as restrições fisiológicas e necessidades psíquicas do usuário (BRÍGIDO, 2015).

Quando os espaços não atendem corretamente aos critérios ergonômicos, essa carência se traduz em inadequações e desconforto aos usuários, como tem-se observado nos ambientes de ensino, mais precisamente nas salas de pranchetas.

A prancheta para desenho pode ser definida, como um mobiliário destinado ao uso de adolescentes e adultos, cuja finalidade é atender as funções pedagógicas de construção/desenvolvimento, leitura e interpretação de desenhos técnicos e arquitetônicos. A tarefa de desenvolver desenhos técnicos e arquitetônicos exige de seus executores concentração e dedicação. Porém na maioria das vezes, estes usuários acabam por sacrificar a sua postura e a qualidade de seus trabalhos, em função do desconforto que sentem ao utilizar tal equipamento (FREITAS E CARVALHO, 2015).

Frequentemente, essas posturas são adquiridas inconscientemente, causadas por deficiência nos mobiliários ou posto de trabalho, pelo uso prolongado dos equipamentos ou pela exigência que o trabalho propõe. Em conjunto com outros fatores físicos, esse mobiliário é o elemento que mais influência circunstancialmente no comportamento, no desempenho e no conforto dos alunos, sendo assim necessário ser um instrumento facilitador na execução de suas tarefas (SILVA, SILVA et al., 2015). Haja vista quando há uma satisfação aos requisitos ergonômicos consequentemente há um melhor funcionamento nas atividades desenvolvidas pelos alunos, contribuindo na relação ensino aprendizagem e saúde/bem-estar dos usuários. 
Deste modo, o presente artigo visa avaliar uma sala de pranchetas, listando os possíveis problemas existentes no espaço, através de um comparativo entre a adaptabilidade dos espaços e as atividades nele desenvolvidas, para uma identificação das variáveis presentes no ambiente que facilitam ou inibem o desempenho das atividades.

\section{METODOLOGIA}

Com o intuito de proporcionar resultados mais consistentes no que se refere às recomendações e proposições que visa esta pesquisa, se fez necessário à utilização de múltiplas técnicas para coleta e interpretação de dados, através dos conhecimentos da Metodologia do ambiente construído, da Antropometria e da Biomecânica Ocupacional.

\subsection{Metodologia do Ambiente Construído}

Para realização da presente pesquisa optou-se pela Metodologia Ergonômica do Ambiente Construído - MEAC, desenvolvida por Villarouco (2008), também chamada de Ergonomia Ambiental, constitui um estudo sistemático para análise de ambientes, em busca de compreender a interação dos usuários com os espaços construídos a partir de aspectos sociais, culturais, psicológicos, fisiológicos e organizacionais. Tendo como base a Análise Ergonômica do Trabalho (AET) que segundo lida (IIDA, 2005) tem por objetivo aplicar os conhecimentos da ergonomia para analisar, diagnosticar e corrigir uma situação real de trabalho.

A MEAC é compreendida por três etapas: Análise Física, Análise da Percepção do Usuário e Diagnóstico Ergonômico. A primeira etapa de ordem física é composta por três fases: Análise global do ambiente, Identificação da configuração ambiental e Avaliação do ambiente construído em uso no desempenho das atividades. A Análise Global do Ambiente consiste em realizar a análise da configuração espacial de forma mais abrangente, com a descrição da sala em uso e a avaliação do ambiente através da observação do pesquisador, em conjunto com as considerações dos usuários do espaço. Na etapa da Identificação da Configuração Ambiental identificam-se todos os condicionantes físico-ambientais, tais como dimensionamento, iluminação, ventilação, ruído, temperatura, fluxos, layout, mobiliários, materiais de revestimento e condições de acessibilidade. A Avaliação do Ambiente em uso no Desempenho das Atividades cuida da observação do ambiente em uso, procedendo a uma análise efetiva da realização do trabalho, com foco no desempenho do espaço construído. (Costa, Andreto et al., 2010)

A Percepção Ambiental do Usuário busca investigar as impressões e expectativas dos usuários em relação ao seu espaço de trabalho. A ferramenta utilizada para alcançar tal objetivo é a Constelação de Atributos, amplamente aplicada nas pesquisas de Villarouco (SILVA, SILVA et al., 2015). Para a construção deste gráfico, são adotados os procedimentos: avaliar a imagem simbólica do indivíduo em frente ao espaço, com a realização da seguinte pergunta: "Quais são as imagens ou ideias que lhe vêm à mente quando você pensa em uma sala de pranchetas?" e, posteriormente, são obtidos dados através da pergunta relacionada ao ambiente de estudo:" Quais são as imagens ou ideias que lhe vêm à mente quando você pensa nessa sala de pranchetas?". Após a obtenção das respostas, estas são categorizadas e organizadas em ordem decrescente por quantidade de vezes que é citada. As variáveis são representadas graficamente, onde os atributos mais citados aparecem mais próximos ao núcleo (COSTA, ANDRETO et al., 2010).

Com os dados coletados parte-se para o Diagnóstico Ergonômico do Ambiente, no qual é realizado o confronto entre o resultado das observações realizadas pelo pesquisador, das interações com os diversos atores investigados e dos elementos da percepção dos usuários obtidos a partir da aplicação de ferramentas da psicologia ambiental. Análises e recomendações são geradas a partir da confrontação dos dados obtidos nessas duas fases, que apresentam as possíveis interferências no desempenho geral do sistema. 
Por se tratar de uma pesquisa em andamento, as duas últimas etapas mencionadas anteriormente (Análise da Percepção do usuário e Diagnóstico Ergonômico) não serão abordadas de forma mais aprofundada, tendo em vista serem concretizadas no início do segundo semestre letivo (2016.2) da instituição de ensino citada.

\subsection{Antropometria}

A antropometria é a ciência que tem por finalidade a medição sistemática e análises quantitativas das variações dimensionais do corpo humano. Objetivando registrar esquematicamente e analisar as incompatibilidades entre o posto de trabalho e os usuários de forma comparativa.

Segundo PEQUINI (2005), o objetivo da antropometria é obter dados sobre as medidas do corpo que descreva com confiabilidade as características, capacidades de alcance, superfície de trabalho para o uso normal e máximo, ângulos de conforto, distribuição de peso, volume, etc., para grupos, raças ou descendência estudada.

Como se sabe, todas as populações são compostas de indivíduos de diferentes tipos físicos e biótipos que apresentam diferenças nas proporções de cada segmento do corpo (PEQUINI, 2005). Sendo assim uma das maneiras mais fáceis e práticas de se usar os dados antropométricos é a utilização de manequins antropométricos bidimensionais dos usuários extremos. Esses manequins são desenhos que representam o homem e a mulher dos percentis extremos (maior e menor) da população usuária, construídos a partir das medidas interarticulares do corpo humano em conjunto com os volumes do tronco e dos membros (QUARESMA E MORAES, 2001).

Desse modo o dimensionamento do produto ou posto de trabalho pode ser conformado e arranjado aos usuários extremos para que nenhum dos dois seja prejudicado, a partir do posicionamento dos manequins na estação de trabalho, permitindo a análise das relações dimensionais entre usuário e posto de trabalho, bem como a identificação das incompatibilidades existentes no conjunto que possam interferir no conforto, na usabilidade produtividade e do produto e na segurança do usuário e do sistema, como por exemplo, os requisitos de visibilidade e ângulos biomecânicos de conforto. (BRÍGIDO, 2015)

\subsection{Biomecânica Ocupacional}

A Biomecânica ocupacional é área de biomecânica que possui como objeto de estudo o universo organizacional, atendo-se especialmente as interações musculoesqueléticas, estáticas ou dinâmicas, que o trabalhador adota em seu posto de trabalho, propiciando um suporte científico para a adaptação dos postos de trabalho aos limites e capacidades do corpo, envolvidos na manutenção de posturas, movimentos inadequados e esforço por tempo prolongado.

A postura assumida pelos usuários está associada às exigências da tarefa para seu desenvolvimento. Postura pode ser definida como estudo do posicionamento relativo de partes do corpo, como cabeça, tronco e membros, no espaço. (DUL E WEERDMEESTER, 2012). No caso desta pesquisa a postura adotada é a sentada.

Embora afirmem que há benefícios na postura sentada, como relaxamento dos músculos e diminuição da pressão hidrostática, resultando em uma menor resistência para o retorno do sangue ao coração, a postura sentada também apresenta desvantagens. Os músculos abdominais tendem a se afrouxar, a espinha tende a se curvar e o funcionamento de órgãos internos como os do sistema digestivo e respiratório, torna-se mais difícil (COSTA; ANDRETO; VILLAROUCO, apud MORAES; PESQUIM, 2010).

Outro fator importante no desenvolvimento de posturas inadequadas é a deficiência das máquinas, equipamentos e postos de trabalho. Devido a essas inadequações os alunos acabam adotando posturas inapropriadas como: inclinação para frente sem usar o encosto 
da cadeira, debruçam sobre as pranchetas, inclinação lateral do tronco e da cabeça, não mantêm a coluna ereta ao desenhar e sentam-se na cadeira sem apoio confortável para os pés. Todas essas posturas podem causam dores corporais, fadiga e doenças ocupacionais como: distúrbios osteomusculares relacionados ao trabalho - DORT, lesões por traumas cumulativos - LTC ou lesões por esforços repetitivos - LER, com a possibilidade de se perpetuar por toda a vida (IIDA, 2012).

Sendo assim, é através dos conhecimentos adquiridos na Biomecânica que se aplicam os métodos como instrumento de medição, registro da avaliação dos constrangimentos corporais envolvidos na sustentação da postura já que, segundo lida (2012), uma simples observação visual não é suficiente para análise detalhada de determinadas posturas.

Uma maneira de realizar de tal avaliação é pelo método de avaliação rápida do corpo inteiro (RAPID ENTIRE BODY ASSESSMENT, REBA). Esse método foi desenvolvido por Hignett e Mcatamney como uma ferramenta de avaliação de posturas dinâmicas e estáticas, para identificar riscos biomecânicos, a existência de mudanças bruscas posturais ou posturas instáveis adotadas durante a atividade realizada. Essa avaliação envolve os membros superiores e inferiores, tronco e pescoço, considerando os fatores carga ou força manuseada e tipo de garra, indicando a necessidade de implantação de medidas corretivas e a urgência de intervenção (OLIVEIRA et al, 2009).

\section{APLICAÇÃO DA MEAC}

\subsection{Análise Global do Ambiente}

A instituição de Ensino Superior em estudo localiza-se na cidade de Teresina/Piauí, e iniciou suas atividades pedagógicas no ano de 2000. É formada por cinco edificações, quatro delas destinadas ao desenvolvimento das atividades acadêmicas e uma destinada às atividades administrativas. A sala em estudo encontra-se na edificação de maior dimensionamento físico e maior infraestrutura em termo de salas de aulas e laboratórios para as realizações das atividades acadêmicas.

Atualmente a instituição oferece vagas semestralmente para os cursos de bacharelado em Administração, Direito, Enfermagem, Serviço Social, Arquitetura e Urbanismo e Engenharia Civil e tecnólogo em Design de interiores.

A infraestrutura disponível para a realização das atividades consiste em salas de aula, laboratórios de informática, biblioteca, auditório, tal como laboratórios e salas específicas para cada curso, Juizado Especial, salas de pranchetas, laboratórios de desenho, oficina de maquetes, mecânica dos solos, topografia, anatomia, microbiologia, etc.

No momento atual, a instituição possui quatros salas de pranchetas com configurações espaciais semelhantes, por esse motivo o método será aplicado em uma das salas na condição em que esta é a utilizada com maior frequência pelos alunos.

A sala escolhida é utilizada, pelos alunos dos cursos de Arquitetura e Urbanismo, Engenharia Civil e Design de interiores, em diversas disciplinas de cunho técnico e arquitetônico, entre elas estão Desenho técnico e arquitetônico, Perspectiva, Desenho técnico básico, Desenho projetivo I, Desenho projetivo II e outras, distribuídas nos turnos de manhã, tarde e noite.

O acesso para a instituição é realizado por duas entradas principais, através do sistema de catracas com identificação eletrônica e, em casos eventuais, utiliza-se o portão de entrada de visitantes ou pessoas que não o possuem o cadastro eletrônico, controlada pelo segurança que permanece no local. No entanto ao entrar, é inexistente qualquer sinalização que oriente ou facilite o acesso e deslocamento para os pontos de interesse, com exceção de algumas salas e laboratórios que possuem placa de identificação, ressaltando que o tamanho e a posição inserida deixam a desejar. Para ter acesso à sala, os alunos percorrem 
o pátio central de convivência, fazendo o uso de escadas ou rampas para acessar e para sair deste pátio, até poder acessar a sala.

A sala tem capacidades para 36 alunos, que a utilizam para realização das atividades pedagógicas juntamente com os professores e, eventualmente, um monitor de determinada disciplina. Em turnos opostos às aulas, é habitual os alunos utilizarem a sala para continuação ou conclusão dos estudos em que foram iniciados. De modo geral, trata-se de um ambiente limpo e organizado, considerando que este foi construído para funcionar como um estabelecimento comercial, necessitando ser adaptado para um estabelecimento de ensino. Apesar das adaptações o ambiente ainda apresenta estruturas relacionadas ao comércio, que frequentemente dificultam o desenvolvimento das atividades.

Figura 1. Sala de pranchetas.

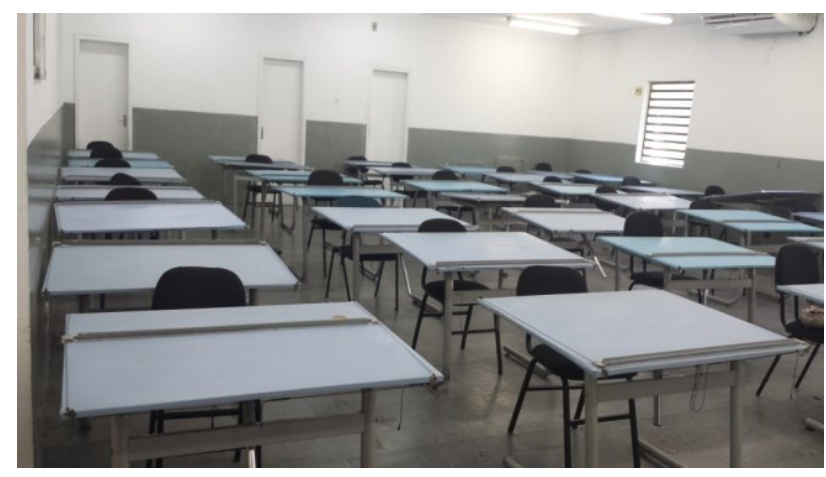

Fonte: Os autores.

\subsection{Identificação da Configuração Ambiental}

Nessa etapa contemplou-se o levantamento dos condicionantes físico-ambientais, tais como: dimensionamento, mobiliário, layout, materiais de revestimento e acabamento, fluxos, temperatura, iluminação, ruído e acessibilidade. Para isso, foi utilizada trena metálica, trena a laser, luxímetro, decibelímetro e termômetro digital.

As dimensões dos ambientes e aspectos relativos a layout, materiais de acabamento e revestimento e instalações foram comparadas ao que é estabelecido pelo Código de Obras e Edificações de Teresina (Lei Complementar $n^{\circ} 3.608$ de janeiro de 2007) e pelo MEC através do Programa Brasil Profissionalizado. Vale ressaltar que a sala de desenho na qual é referida o último comparativo refere-se às salas de desenho com o uso de microcomputadores, deixando a desejar a ausência de recomendações relativas ao uso de pranchetas, com isso não foram levadas em considerações todas as proposições. Ademais as NRs e NBRs da ABNT.

Segundo o artigo 220 do Código de Obras e Edificações de Teresina, as escolas de ensino superior e as escolas complementares devem obedecer às mesmas prescrições relativas aos estabelecimentos comerciais. Considerando que a área mínima das edificações em função de sua destinação e sua capacidade (área bruta por pessoa) seja de 9,00 $\mathrm{m}^{2}$. Ainda, de acordo com tal lei, as salas de instituições de educação superior, independente do uso, devem conter um círculo inscrito de no mínimo $2,50 \mathrm{~m}$, área mínima de uma sala de 12,00 $\mathrm{m}^{2}$, os vãos de iluminação, ventilação e insolação natural de edifícios não residenciais, estes devem ser, no mínimo, $1 / 6$ da área útil do ambiente e com pé direito mínimo de 2,60 m. 0 MEC, através do Programa Brasil Profissionalizado recomenda que a área útil mínima para salas de desenho deva ser de $80,00 \mathrm{~m}^{2}$.

Como já citado nesta pesquisa, não há disponibilidade de recomendações que envolva, com consistência, todos os dados relevantes para o desenvolvimento de uma sala de 
pranchetas, sendo assim não há referências comparativas, como por exemplo, para configuração quantitativa de pranchetas por sala.

No que se referem aos requisitos de dimensionamentos mínimos, a sala atende à norma, possui $99,29 \mathrm{~m}^{2}(7,88 \times 12,60 \mathrm{~m})$ e pé direito de $3,00 \mathrm{~m}$. Porém ao comparar a área exigida por aluno e quantidade de pranchetas em sala, observa-se um valor muito abaixo do mínimo estabelecido pelo Código de Obras e Edificações de Teresina, totalizando 2,76 $\mathrm{m}^{2}$ por aluno.

Com relação ao layout, o MEC considera que a instituição poderá dispor equipamentos, ferramental e mobiliário de acordo com suas necessidades, desde que garantam condições favoráveis para instalação daqueles equipamentos que ficarão a cargo dos fornecedores. A sala é composta por 36 pranchetas de tamanho $A 1(1,0 \times 0,72 \times 0,80 \mathrm{~m}) \mathrm{com}$ regulagem de inclinação e 36 cadeiras distribuídas em cinco filas cada um com sete pranchetas, com exceção de uma que apresenta oito pranchetas, essas se encontram alinhadas e paralelas entre si. Segundo IIDA (2012) as tarefas que exigem um acompanhamento visual contínuo devem ser feitas em superfície inclinada, como no caso de desenhos, leituras e inspeções de qualidade, do contrário será necessário inclinar a cabeça e o tronco para frente. No caso de leitura/desenho a inclinação recomendada é 45 graus e para escrever a inclinação é 15 graus.

Além das pranchetas, conta-se a mesa $(1,20 \times 0,75 \times 0,60 \mathrm{~m})$ e a cadeira $(0,40 \times 0,85 \times 0,40$ $\mathrm{m})$ do professor. Tal cadeira é do mesmo modelo e material utilizado pelos alunos, não possui regulagem de altura e possui acabamento em estofado. $O$ armário em aço $(0,93 \mathrm{x}$ $1,98 \times 0,33 \mathrm{~m}$ ) serve para guardar os pertences utilizados em aula. Além disso, contém quadro branco $(3,0 \times 1,20,0,95 \mathrm{~m})$, quadro de avisos $(0,70 \times 0,50 \times 1,20 \mathrm{~m})$ e um projetor de multimídia (Data Show), que segundo o MEC é recomendado uma tela de Projeção acima do quadro branco, porém a mesma não existe.

A inexistência de espaço para a alocação de instrumentos/materiais de desenho no momento do uso, e para os objetos pessoais dos alunos faz que estes sejam colocados no chão, ou sobe as cadeiras, prejudicando a realização de tarefas e diminuição da área de trabalho.

Para o MEC os equipamentos de segurança, do tipo extintor e luz de emergência, deverão ser instalados pela escola em locais apropriados de maneira que garanta a segurança do ambiente.

Comparativamente os materiais de revestimento e acabamento de acordo com o MEC em relação a piso e paredes, diz que piso deve ser impermeável, antiderrapante, resistente mecânica e quimicamente e não deve apresentar saliência nem depressões que prejudiquem a circulação de pessoas ou a movimentação de materiais. O cerâmico comum é o mais recomendável pelo seu baixo custo, facilidade na colocação e limpeza, segurança oferecida, ótima resistência e durabilidade. As paredes devem ser claras, foscas e impermeáveis, revestidas com material que permita o desenvolvimento das atividades em condições seguras, sendo resistentes ao fogo e a substâncias químicas, além de oferecer facilidade de limpeza. O piso utilizado é cerâmico vinilo $30 \times 30 \mathrm{~cm}$, na cor cinza, possuindo algumas áreas danificadas e irregulares, realçadas pela ausência de pedras cerâmicas. As paredes são pintadas na cor branca e cinza, o cinza é pintado com tinta impermeável que vai do piso a $1,30 \mathrm{~m}$ de altura, a cor branca dar continuidade até o teto. Entretanto foram encontrados diversos focos de infiltrações na parede. $\mathrm{E}$ o forro é de gesso do tipo pé solto.

Segundo o MEC no que se refere às esquadrias, as janelas e portas devem ser amplas e distribuídas de tal forma que permitam uma boa iluminação e arejamento da sala. Recomenda-se janelas basculantes, por apresentarem maior segurança e por serem facilmente abertas e fechadas com um só comando de mão, além de serem localizadas acima dos equipamentos, numa altura aproximada de $1,20 \mathrm{~m}$ do nível do piso. Para controle de raios solares, devem ser instaladas persianas metálicas ou breezes (anteparos externos instalados nas janelas que impeçam a entrada de raios solares, mas não impeçam a entrada de claridade). É necessário a emprego de materiais de construção e acabamentos que 
retardem o fogo, que proporcionem boa vedação, sejam lisos, não porosos, de fácil limpeza e manutenção. Como medida de segurança, as portas devem sempre abrir para o lado de fora e recomenda-se que tenha mais de uma porta.

Nas salas são utilizadas janelas basculantes com vidro jateado de 1,20 m de altura, 1,0 m de largura e 1,20 m de peitoril, e não apresentam sistema de controle de raios solares. A porta de entrada é de metalon branco com vidro transparente, não possui abertura para fora e vão com $0,80 \mathrm{~m}$ de largura. Além de quatro portas que dão acesso para depósitos, como já foi citada a unidade tratava-se de um ambiente comercial. Ressalta-se que as janelas ficam permanentemente fechadas, comprometendo a ventilação.

Com relação às instalações elétricas, a sala possui 4 tomadas baixas e 4 tomadas altas e 4 caixas de distribuição de circuitos, com apenas um em funcionamento. Possui dois interruptores, um referente ao data show e outro para um ar condicionado do tipo janeleiro que não está em funcionamento. Os ares condicionados e luminárias são ligados direitos no quadro de distribuição em funcionamento.

No que se refere às características específicas ao conforto iluminístico, térmico e umidade e acústico, os resultados foram comparadas com as suas respectivas normas: NBR 8985, NR 17 e NBR 10.152. Vale destacar que as medições foram feitas com os laboratórios desocupados. Assim, a presença dos alunos pode representar um aumento dos níveis de temperatura e ruído no ambiente, prejudicando ainda mais as condições de conforto encontradas nos laboratórios. Abaixo encontram-se a planta baixa com as locais das medições.

Figura 2. Pontos de lluminação da Sala.

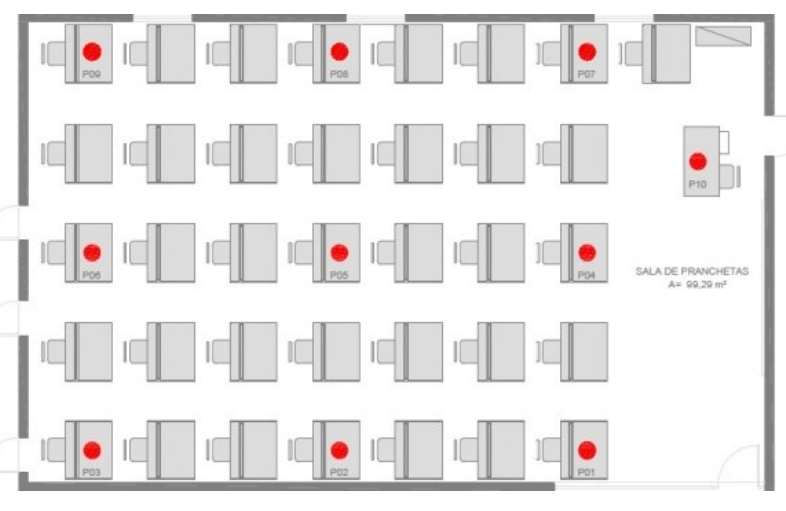

Fonte: Os autores.

Segundo a NBR 8985 uma boa iluminação propicia segurança e desenvolvimento de maneira precisa, eficiente e segura das atividades, sem causar desconforto e fadiga visual. A presente norma considera estabelece a média de iluminação adequada de 750 lux, a medida encontrada foi 384,5 lux desconsiderando a medição próxima a mesa do professor. Como pode-se observar os valores encontra-se fora dos padrões da norma. Vale ressaltar que esses valores são influenciados pela iluminação natural através das 3 janelas presentes e pela porta de entrada em vidro. Para luminárias o MEC recomenda o uso do tipo de embutir, com lâmpadas fluorescentes e que contenha proteção. $\mathrm{Na}$ sala são usas 18 luminárias do tipo sobrepor com duas lâmpadas fluorescentes em cada e não possui proteção.

Em relação às condições de conforto térmico e de umidade foram comparadas com a NR 17 (MINISTÉRIO DO TRABALHO E EMPREGO, 2007) que estabelece uma faixa de temperatura entre $20^{\circ} \mathrm{C}$ e $23^{\circ} \mathrm{C}$ e umidade não inferior a $40 \%$ para locais de trabalho onde são executadas atividades que exijam solicitação intelectual e atenção constantes. Todo o sistema de refrigeração é feito através de 2 condicionadores de ar do tipo Split, na sala são 3 ares condicionados, dois do tipo Split e o outro do tipo janela. No momento da medição 
apenas um estava em funcionamento. Dos 10 pontos medidos, todos mostram valores acima do recomendado em até $3,1^{\circ} \mathrm{C}$. No que se refere à umidade, todos os valores encontra-se fora dos padrões estabelecidos, o menor possui $44,70 \%$ e a maior $47,6 \%$.

No que diz respeito ao conforto acústico, os resultados encontrados foram comparados com os índices definidos pela NBR 10.152, que determina entre $40 \mathrm{~dB}$ e $50 \mathrm{~dB}$ o ruído aceitável para ambientes de ensino, quando superiores a este são considerados desconfortáveis, sem necessariamente implicar risco de danos à saúde. Ruído é caracterizando por barulhos ou som indesejável, segundo IIDA (2005) um estímulo auditivo que não contém informações úteis para a tarefa em execução, pode ser considerado também como poluição sonora não desejada. Os valores encontrados estão todos a cima do permitido, com o menor de $50,70 \mathrm{~dB}$ e o maior de $62,60 \mathrm{~dB}$, correndo o risco de apresentar sérios riscos auditivos aos alunos, além de prejuízo a concentração.

Com a relação à acessibilidade, leva-se em consideração as diretrizes propostas pela NBR 9050. Observou-se uma situação crítica, conforme as possibilidades de uso por pessoas com cadeira de rodas. Considerando os giros de 90 e 360 graus, é possível apenas nas áreas próxima a entrada, entre as pranchetas é totalmente inviável, possuindo apenas em média $0,70 \mathrm{~m}$ de vão, o mínimo exigido pela norma é $0,80 \mathrm{~m}$.

Figura 3. Planta baixa com as possibilidades de circulação de pessoas com cadeiras de rodas

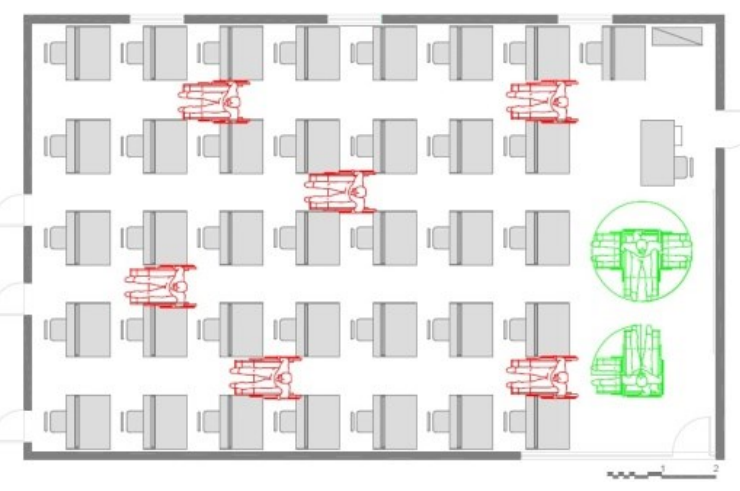

Fonte: Os autores

\subsection{Avaliação do Ambiente em Uso no Desempenho das Atividades}

Com base no que foi observado na rotina acadêmica dos alunos, professores e funcionários, o fluxo geral em toda instituição é intenso ao longo do dia. Na sala, o fluxo varia de acordo com o número de alunos por disciplina, a menor turma possui 17 alunos e maior 31 alunos, considerando as disciplinas ministradas durante o período letivo na qual foram coletados os dados. A circulação da sala, de modo geral, é intensa na área próxima a entrada e o quadro branco, na qual encontra-se o maior espaço de circulação da sala. Porém, torna-se insuficiente quando se trata de espaços livres para circulação ou permanência de mais de uma pessoa entre as filas das pranchetas, como opção é necessário um esquivasse e outro passar ou um ceder à passagem para o outro. Essa situação é agravada com a permanência de materiais de desenho e objetos pessoais ao chão, tendo em vista que não há lugares adequados para o armazenamento dos mesmos. Quando há permanência de duas pessoas posicionadas na lateral, ainda é possível a passagem, porém não a mais confortável, o mesmo acontece próxima a mesa do professor, por conta do armário. Essa situação é resultado do excesso de pranchetas na sala, comprometendo a circulação e conforto dos usuários. 
Figura 4. Planta baixa com as possibilidades de circulação de pessoas ( circulação ótima, circulação desejável, circulação reduzida)

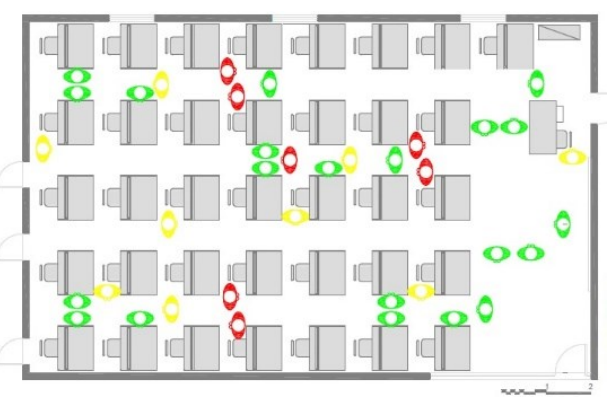

Fonte: Os autores

Sendo assim reforça-se a importância de um estudo detalhado das tarefas, considerando os espaços dos equipamentos e materiais necessários, assim como o espaço utilizado para manuseio desses elementos, integrando à análise com maior profundidade os riscos posturais envolvidos no uso desse mobiliário, por meio dos conhecimentos da Antropometria e Biomecânica ocupacional, através da aplicação da avaliação custo postural e dados antropométricos.

\subsubsection{Avaliação Antropométrica}

Para a avaliação antropométrica e identificação dos pontos de inadequações, foi adotado a aplicação de manequins antropométricos bidimensionais empregados na conformação e dimensionamento de estações de trabalho e mobiliários.

$O$ posto de trabalho refere-se às pranchetas utilizadas pelos alunos da instituição, como base de apoio para o desenvolvimento das suas atividades pedagógicas proposta pelos professores. O trabalho é realizado na posição sentada, as aulas possuem duração de 100 a 150 minutos dependendo do quadro de horário determinado pelas coordenações dos cursos.

A população usuária em questão é formada por adultos dos gêneros feminino e masculino. Para que o posto de trabalho possa atender o maior número de usuários, adotou-se a porcentagem da população de $90 \%$, considerado o percentil 5,0 feminino e o percentil 95,0 masculino, baseado nas dimensões básicas antropométricas proposta por Panero e Zelnik.

A figura a seguir mostra a análise da compatibilização entre os usuários e o posto de trabalho para ambos percentis:

1 - Vista posterior: superfície de trabalho abaixo dos cotovelos, exigindo uma elevação acima da área de conforto para o menor percentil, não há necessidade de elevação dos cotovelos para maior percentil;

2 - Vista lateral: a maior parte da superfície de trabalho encontra-se fora do ângulo de visão para ambos, ausência de apoio para os pés para menor percentil;

3 - Vista superior: superfície de trabalho dentro das áreas de conforto para ambos os percentis.

A partir da aplicação dos dados antropométricos, foi possível identificar qual o principal ponto de inadequação, trata-se da ausência de cadeiras sem regulagens, que tem por consequência a superfície abaixo do cotovelo para menor percentil e a necessidade de um apoio para os pés. A superfície de trabalho no limite inferior do campo para ambos os percentis, demanda a flexão do pescoço para melhor visualização no momento da atividade. 
Figura 5. Antropometria.

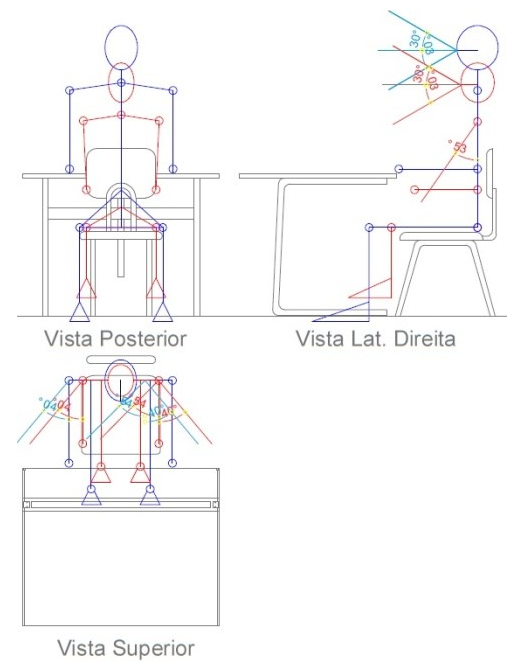

Fonte: PANERO.

\subsubsection{Aplicação do REBA}

Foi adotado uma única postura e o lado direito do usuário para a realização da avaliação.

Figura 6. Usuário no Posto de Trabalho.

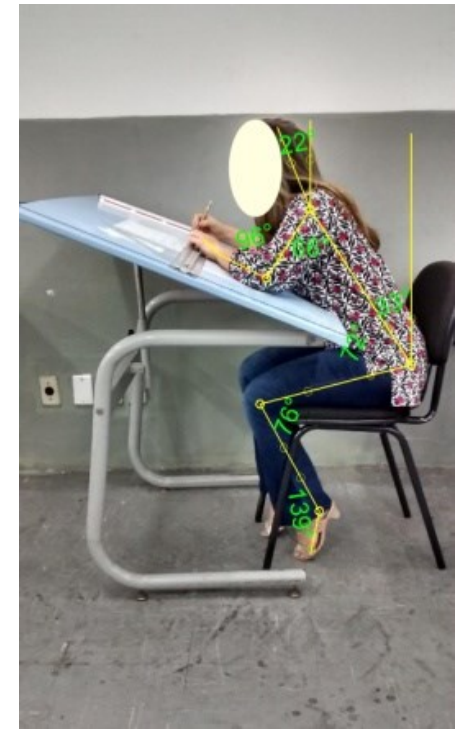

Fonte: Os Autores

A pontuação encontrada para a postura do pescoço, tronco e pernas, foi igual a 5 , a partir dos seguintes valores adotados:

- $\operatorname{Pescoço~}=3:$ flexão $>20^{\circ}+1$ para ajuste de inclinação

- $\quad$ Tronco = 3: flexão entre $20^{\circ}$ e $60^{\circ}$;

- Pernas (trabalho sentado) $=1$ : flexão entre $90^{\circ}$ e $60^{\circ}$.

Com relação à postura de braço, antebraço e punho, o valor encontrado foi igual a 6 , a partir das seguintes pontuações: 
- Braço $=5$ : flexão $>90^{\circ}+1$ para ajuste de abdução + para ajuste de elevação -1 para ajuste de elevação

- Antebraço $=1$ : flexão entre $60^{\circ}$ e $100^{\circ}$;

- Punho $=2$ : flexão entre $0^{\circ}$ e $15^{\circ}+1$ para ajuste de rotação do punho.

Assim, a pontuação obtida para riscos músculo esqueléticos foi igual a 7 .

Considerando que o aluno passa mais de um minuto nesta posição, foi feito ajuste de tempo de atividade, acrescentando um ponto a esse valor, obtendo pontuação final igual a 8 . Não foram necessários ajustes de força nem de pega neste caso. Partindo disso, é possível indicar o médio risco de distúrbios músculo esqueléticos sendo necessária uma investigação mais aprofundada para proposição de mudanças.

\subsection{CONCLUSÃO}

Os resultados obtidos até esta fase do trabalho comprovam que a aplicação dos conhecimentos da ergonomia, enquanto área multidisciplinar e aplicada, pode contribuir de forma bastante positiva para melhoria no desempenho e qualidade de vida do usuário, apontando soluções ou minimizando e prevenindo os danos à saúde e ao bem-estar. Quanto mais rápido forem utilizadas as ações da ergonomia, melhor será para o usuário final, pois o futuro do trabalho aplicado ao ser humano começa hoje.

\subsection{REFERÊNCIAS BIBLIOGRÁFICAS}

BRÍGIDO, B. S. F. Avaliação Ergonômica do Ambiente em Laboratórios de Enfermagem de Educação Superior. Recife - PE, 2015.

COSTA, A. P. L.; ANDRETO, L.; VILLAROUCO, V. Avaliação de Escritorios Panoramicos Apartir de uma Metodologia Ergonomia. $13^{\circ}$ Encontro Nacional de Tecnologia do Ambiente Construído - ENTAC, 2010. Canela - RS.

DUL, J.; WEERDMEESTER, B. Ergonomia Prática. $3^{a}$ Edição. São Paulo - SP: Edgard Blücher, 2012. ISBN 9788521203490.

FREITAS, S. F. D.; CARVALHO, A. P. D. A. C. S. S. M. Recomencações para o Design de Sistemas de Desenvolvimentos de Desenhos Tecnicos: Analise Ergonomica das Pranchetas Para Desenhos nas Salas de Aula do IFBA Campus de Salvador. $15^{\circ}$ Congresso Brasileiro de Ergonomia, ABERGO, 2015. Recife - PE.

IIDA, I. Ergonomia: Projeto e Producao. São Paulo - SP: Edgard Blucher, 2005. ISBN 97885-212-0354-4.

PEQUINI, P. C. Intervenção Ergonomica e Suas Implicações na Produtividade e Satisfação dos Funcionarios: Estudo de Caso de Lavanderia Industrial. 2007. Dissertação de Mestrado

PEQUINI, S. M. Ergonomia aplicada ao design de produtos: um estudo de caso sobre o design de bicicletas. 2005. USP, São Paulo - SP.

QUARESMA, M. M. R.; MORAES, A. D. A Aplicação de Dados Antropométricos em Projetos de Design: Como Projetar Corretamente Produtos Ergonômicos. 2001. Pontifícia Universidade Católica do Rio de Janeiro (PUC - Rio), Rio de Janeiro - RJ.

SILVA, A. C. C. L. et al. Avaliação Ergonomica do Ambiente Construido: Estudo de Caso no Arquivo Funcional de uma Instituição Pública de Ensino Superior. $15^{\circ}$ Congresso Brasileiro de Ergonomia, ABERGO, 2015. Recife - PE. 
VILLAROUCO, V. Construindo uma Metodologia de Avaliação Ergonômica do Ambiente - AVEA. $14^{\circ}$ Congresso Brasileiro de Ergonomia, ABERGO, 2008. Porto Seguro BA.

WEERDMEESTER, BERNAND; BUL, Jan. Ergonomía prática. Tradução: ITIRO IIDA. $3^{\circ}$. Ed. São Paulo: Blucher, 2012. 